\title{
Hepatorenal Functions Following Prolonged Oral Administration of Caffeine on Male Wistar Rats
}

\author{
Ekamadu Hope Ukame ${ }^{1}$, Ojeka Sunday Ogbu ${ }^{1 *}$ and Zabbey Victor Zigabelbari ${ }^{1}$ \\ ${ }^{1}$ Department of Human Physiology, Faculty of Basic Medical Sciences, College of Health Science, University of Port Harcourt, Rivers State, \\ Nigeria.
}

DOI: 10.29322/IJSRP.11.10.2021.p11839

http://dx.doi.org/10.29322/IJSRP.11.10.2021.p11839

\begin{abstract}
Caffeine is the most widely used natural stimulant, found in beverages, medicine and some popular masticatories. The aim of this study was to investigate the effects of prolonged oral administration of caffeine on hepatorenal functions of male Wistar rats. In this study 32 Wistar rats $(120 \mathrm{~g}-240 \mathrm{~g})$ were used. The animals were divided into four groups of 8 rats each with group 1 as control given only feed and water. Group two were given $2 \mathrm{mg} / \mathrm{kg}$ caffeine, group 3 given $4 \mathrm{mg} / \mathrm{kg}$ caffeine and group 4 given $6 \mathrm{mg} / \mathrm{kg}$ caffeine orally for 28 days. The result showed significant decrease in body weight. There was also a statistically significant increase in the concentrations of urea, creatinine, uric acid, bicarbonate and chloride in groups 3 and 4 and a statistically significant decrease in the concentrations of potassium and sodium in groups 3 and 4. A significant increase was found in the concentration of liver enzymes like AST, ALT and ALP in groups 3 and 4. A significant increase was also seen in the concentrations of triglycerides, total cholesterol, low density lipoprotein and total protein in groups 3 and 4 . A histological distortion was seen in the liver of all the test groups and a distortion of the histology of the kidney was seen in test group 4. It was therefore concluded from the study that caffeine can cause electrolyte imbalance, cardiovascular disorders and damage to the liver and kidney and can lead to substantial weight loss especially when consumed for a very long time.
\end{abstract}

Index Terms- Stimulant, caffeine, urea, kidney, electrolyte and hepatorenal.

\section{INTRODUCTION}

$\mathrm{C}$ affeine is a bioactive chemical that can be available in both natural and manufactured forms. It occurs naturally as a stimulant that can be found in cocoa, coffee, and tea well as other beverages. It acts as a stimulant and boosts alertness and memory through its action on the brain and spinal cord. It may have little preventive effect on many diseases. Moderate use of caffeine is associated with various physical effects, including mental performance. Caffeine can also increase muscle strength and can improve muscle endurance .It also improves anaerobic test performance.

Caffeine is mainly broken down by cytochrome P450 enzymes in the liver, which accounts for about $90 \%$ of the caffeine clearance rate. According to parameters such as dosage and previous long-term exposure, caffeine may have harmful or protective effects under certain physiological or pathological conditions. Previous studies have shown that long-term use of caffeine can aggravate liver damage. Carbonated caffeine beverages are also associated with high blood pressure, diabetes and kidney stones, all of which are risk factors for chronic renal failure. Studies have revealed that drinking 3-4 cups of caffeinecontaining foods each day can increase the risk of renal disease and the progression at which kidney function declines. ${ }^{[1]}$

Since caffeine is contained in most daily drinks and teas, so many people are often negatively affected by it. Caffeine has been found to improve alertness and memory, but it can also negatively affect sleep. Caffeine also causes increase in the rate and force of muscle contraction in the heart thereby increasing the blood pressure. Chronic caffeine usage has also been found to hasten the deterioration of renal function in studies. ${ }^{[1]}$ Long term use of caffeine has also been seen to worsen bladder instability and also worsen the rest of those with bladder problems. Caffeine overdose is also related to brain overstimulation and disorientation. In two recent population-based studies (National Health and Nutrition Examination Surveys I and III), higher daily caffeine intake was associated with lower alanine aminotransferase (ALT) and chronic liver disease. Patients who drank more coffee have been reported to have lower levels of aspartate aminotransferase (AST), alkaline phosphate, and direct bilirubin, and higher levels of serum albumin. ${ }^{[2]}$ However, depending on the body size and tolerance, the amount of caffeine required to cause effects differs from person to person.

There are few conflicting studies on lipids in the liver after long-term use of caffeine, and there are no reports on how longterm use of caffeine affects overall liver and kidney function. Therefore, this study aims to evaluate the effects of long-term caffeine consumption on liver and kidney function in experimental animal models

\section{MATERIALS AND METHODS}

This work was designed to validate the effect of prolonged oral caffeine administration on hepatorenal functions using experimental rats for 28 days. A total of 32 male rats were obtained from the animal care unit of the Department of Human Physiology, Faculty of Basic Medical Sciences, College of Health Sciences, University of Port Harcourt. The rats were kept in wooden cages with four compartments, each containing eight rats, and allowed to acclimatize in the Animal House of the University of Port Harcourt for two weeks. The 32 male wistar rats used for 
the study were after acclimatization divided into four groups of

eight rats each as follows;

\section{GROUP}

1

2

3

4

\section{DESCRIPTION}

$$
\begin{aligned}
& \text { Received water }+ \text { Normal rat feed only orally } \\
& \text { Received water }+ \text { rat feed }+2 \mathrm{mg} / \mathrm{kg} / \mathrm{b} . \mathrm{w} \text { of caffeine orally } \\
& \text { Received water }+ \text { rat feed }+4 \mathrm{mg} / \mathrm{kg} / \mathrm{b} . \mathrm{w} \text { of caffeine orally } \\
& \text { Received water }+ \text { rat feed }+6 \mathrm{mg} / \mathrm{kg} / \mathrm{b} . \mathrm{w} \text { of caffeine orally }
\end{aligned}
$$

The caffeine used for this study was caffeine Anhydrous, a product of Loba Chemie PVT. Ltd, Mumbai (India). Each container contains $100 \mathrm{~g}$ of powdered caffeine. The caffeine was purchased from JEOCHEM medical laboratory, Choba Port Harcourt, Rivers state. The quantity and dosage of caffeine administered to the rats was in relation to their body weight.

The rats were sacrificed after 28 days of treatment. Four rats in each group were anesthetized with chloroform. After the sacrifice, blood samples were collected by cardiac puncture to assess liver enzymes, serum lipid / protein profile, renal index, and electrolytes. The liver and kidney were also harvested from each animal for histopathological examination.

The data was analyzed using version 20.0 of SPSS. The analyzed data were displayed in a table. The average comparison (analysis of the experiment) was carried out using ANOVA. The confidence limit of the difference between $95 \%$ of the group was considered significant at $\mathrm{p}<0.05$. The results are shown as a mean and standard error of mean.

\section{RESULTS}

Table 1A: Effect of prolonged caffeine administration on renal indices and electrolytes

$\begin{array}{llllll}\text { Groups } & \begin{array}{l}\text { Urea } \\ (\mathbf{m m o l} / \mathbf{l})\end{array} & \begin{array}{l}\text { Creatinine } \\ (\mathbf{m m o l} / \mathbf{l})\end{array} & \begin{array}{l}\text { Uric Acid } \\ (\mathbf{m m o l} / \mathbf{l})\end{array} & \begin{array}{l}\text { Potassium } \\ (\mathbf{m m o l} / \mathbf{l})\end{array} & \text { Sodium }(\mathbf{m m o l} / \mathbf{l}) \\ \mathbf{1} & 5.4 \pm 0.56 & 102.0 \pm 11.5 & 225.0 \pm 1.96 & 7.1 \pm 0.41 & 148.3 \pm 8.47 \\ \mathbf{2} & 6.1 \pm 0.16 & 103.5 \pm 2.96 & 226.8 \pm 13.4 & 6.5 \pm 0.30 & 135.0 \pm 6.21 * \\ \mathbf{3} & 6.5 \pm 0.42 * & 108.0 \pm 8.39 * & 270.3 \pm 11.93 * & 5.3 \pm 0.90 * & 125.3 \pm 9.09 * \\ \mathbf{4} & 7.5 \pm 0.37 * & 116.0 \pm 7.42 * & 288.0 \pm 26.95 * & 4.4 \pm 0.20 * & 113.0 \pm 3.81 *\end{array}$

Data are expressed as Mean \pm SEM of 4 rats, * is mean significant difference relative to control at $\mathrm{p}<0.05$

Table 1B: Effect of prolonged caffeine administration on renal indices and electrolytes continued

$\begin{array}{llll}\text { Groups } & \text { Magnesium }(\mathbf{m m o l} / \mathbf{l}) & \text { Bicarbonate }(\mathbf{m m o l} / \mathbf{l}) & \text { Chloride }(\mathbf{m m o l} / \mathbf{l}) \\ \mathbf{1} & 1.67 \pm 0.04 & 24.5 \pm 0.96 & 37.3 \pm 1.26 \\ \mathbf{2} & 1.96 \pm 0.03^{*} & 26.0 \pm 0.82 & 44.3 \pm 1.11^{*} \\ \mathbf{3} & 1.98 \pm 0.03^{*} & 38.5 \pm 0.96 * & 57.5 \pm 0.65 * \\ \mathbf{4} & 2.05 \pm 0.01^{*} & 43.0 \pm 0.58 * & 63.5 \pm 0.65^{*}\end{array}$

Data are expressed as Mean \pm SEM of 4 rats, $*$ is mean significant difference relative to control at $\mathrm{p}<0.05$

Table 2: Effect of prolonged caffeine administration on some liver enzymes

$\begin{array}{llll}\text { Groups } & \text { AST (u/l) } & \text { ALT (u/l) } & \text { ALP (u/l) } \\ \mathbf{1} & 22.5 \pm 0.96 & 9.9 \pm 0.62 & 25.0 \pm 3.63 \\ \mathbf{2} & 25.8 \pm 0.48 & 11.5 \pm 0.50 & 27.3 \pm 3.40 \\ \mathbf{3} & 28.5 \pm 0.65^{*} & 20.4 \pm 0.74^{*} & 34.8 \pm 3.47^{*} \\ \mathbf{4} & 40.5 \pm 2.10^{*} & 30.6 \pm 0.34^{*} & 38.0 \pm 0.91^{*}\end{array}$

Data are expressed as Mean \pm SEM of 4 rats, * is mean significant difference relative to control at $\mathrm{p}<0.05$ 
Table 3: Effect of prolonged caffeine administration on Lipid profile and Serum protein

$\begin{array}{lllllll}\text { Groups } & \begin{array}{l}\text { Total } \\ \text { Cholesterol } \\ (\mathbf{m m o l} / \mathbf{l})\end{array} & \begin{array}{l}\text { Triglyceride } \\ (\mathbf{m m o l} / \mathbf{l})\end{array} & \begin{array}{l}\text { High Density } \\ \text { Lipoprotein } \\ (\mathbf{m m o l} / \mathbf{l})\end{array} & \begin{array}{l}\text { Low Density } \\ \text { Lipoprotein } \\ (\mathbf{m m o l} / \mathbf{l})\end{array} & \begin{array}{l}\text { Total Protein } \\ (\mathbf{g} / \mathbf{l})\end{array} & \text { Albumin }(\mathbf{g} / \mathbf{l}) \\ \mathbf{1} & 2.13 \pm 0.15 & 0.54 \pm 0.13 & 0.96 \pm 0.17 & 1.41 \pm 0.05 & 67.00 \pm 1.96 & 39.50 \pm 1.32 \\ \mathbf{2} & 2.15 \pm 0.06 & 0.89 \pm 0.05^{*} & 1.12 \pm 0.05 & 1.44 \pm 0.01 & 68.25 \pm 2.32 & 41.75 \pm 1.70 \\ \mathbf{3} & 3.33 \pm 0.13^{*} & 0.91 \pm 0.01^{*} & 1.29 \pm 0.19^{*} & 2.65 \pm 0.31^{*} & 79.25 \pm 2.18^{*} & 43.50 \pm 1.04^{*} \\ \mathbf{4} & 4.05 \pm 0.10^{*} & 0.96 \pm 0.09^{*} & 1.93 \pm 0.10^{*} & 3.56 \pm 0.15^{*} & 82.75 \pm 2.06^{*} & 45.00 \pm 1.08^{*}\end{array}$

Data are expressed as Mean \pm SEM of 4 rats, * is mean significant difference relative to control at $\mathrm{p}<0.05$

Table 4: Effect of prolonged caffeine administration on Body weight

$\begin{array}{lllllll}\text { Groups } & \text { Week 0 } & \text { Week 1 } & \text { Week 2 } & \text { Week 3 } & \text { Week 4 } & \text { Wk4-Wk 0 } \\ \mathbf{1} & 137.0 \pm 6.06 & 144.1 \pm 6.32 & 142.0 \pm 6.71 & 147.5 \pm 5.81 & 150.6 \pm 5.43 & 13.63 \\ \mathbf{2} & 159.9 \pm 1.86 & 159.1 \pm 1.96 & 160.3 \pm 1.89 & 160.3 \pm 1.90 & 159.0 \pm 1.87 & -0.88 \\ \mathbf{3} & 181.9 \pm 2.43 & 178.8 \pm 2.16 & 180.6 \pm 2.46 & 175.9 \pm 1.48 & 173.9 \pm 1.38 & -8.0 \\ \mathbf{4} & 222.1 \pm 8.75 & 214.5 \pm 7.58 & 218.6 \pm 8.52 & 211.1 \pm 7.16 & 200 / 3 \pm 2.84 & -21.88\end{array}$

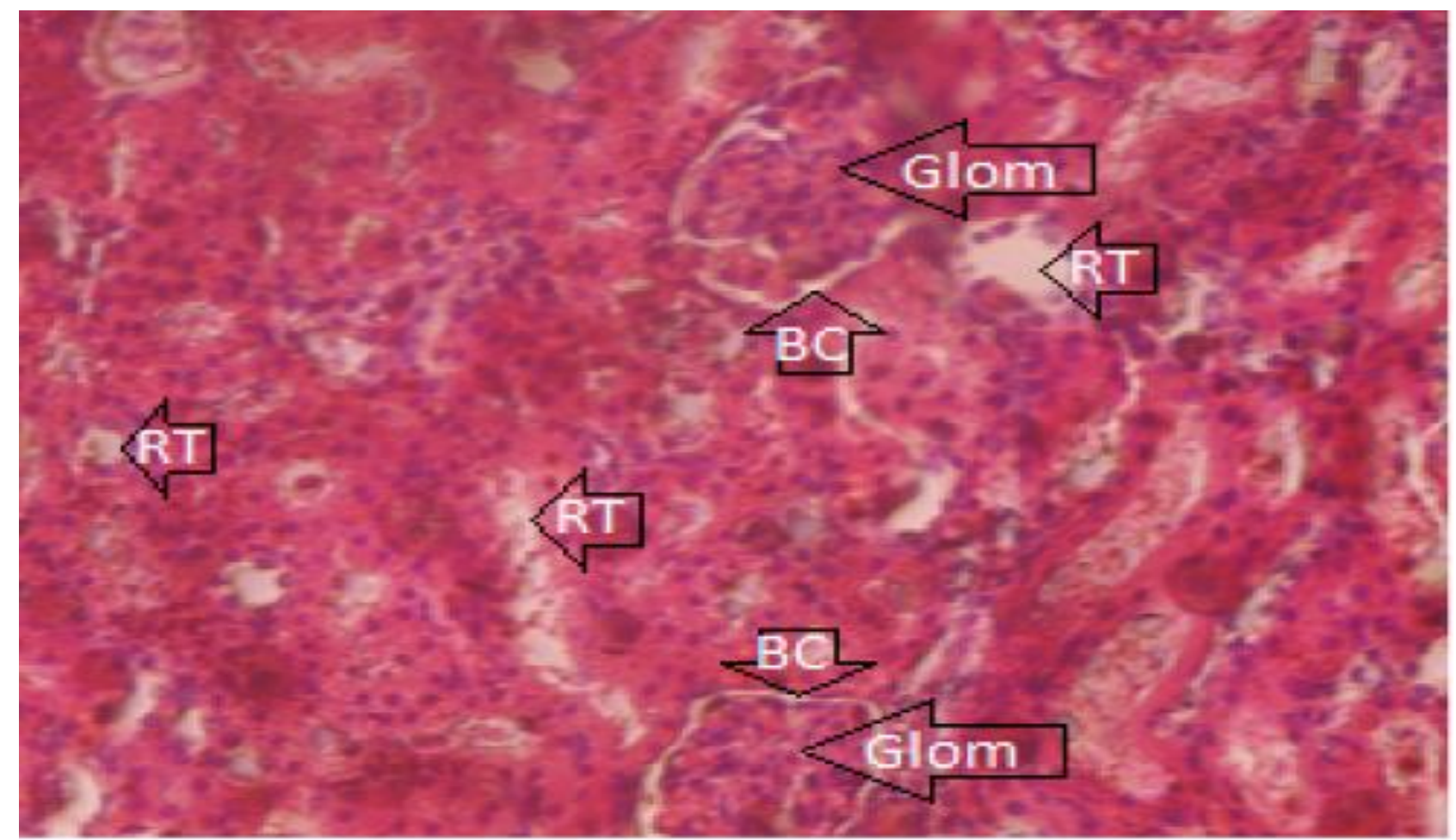

Plate 1: Photomicrograph of a section of the Liver of rat (control group) after 28 days period. It reveals a histologically normal liver, showing normal Hepatocytes (Hep) and sinusoids (sin). 


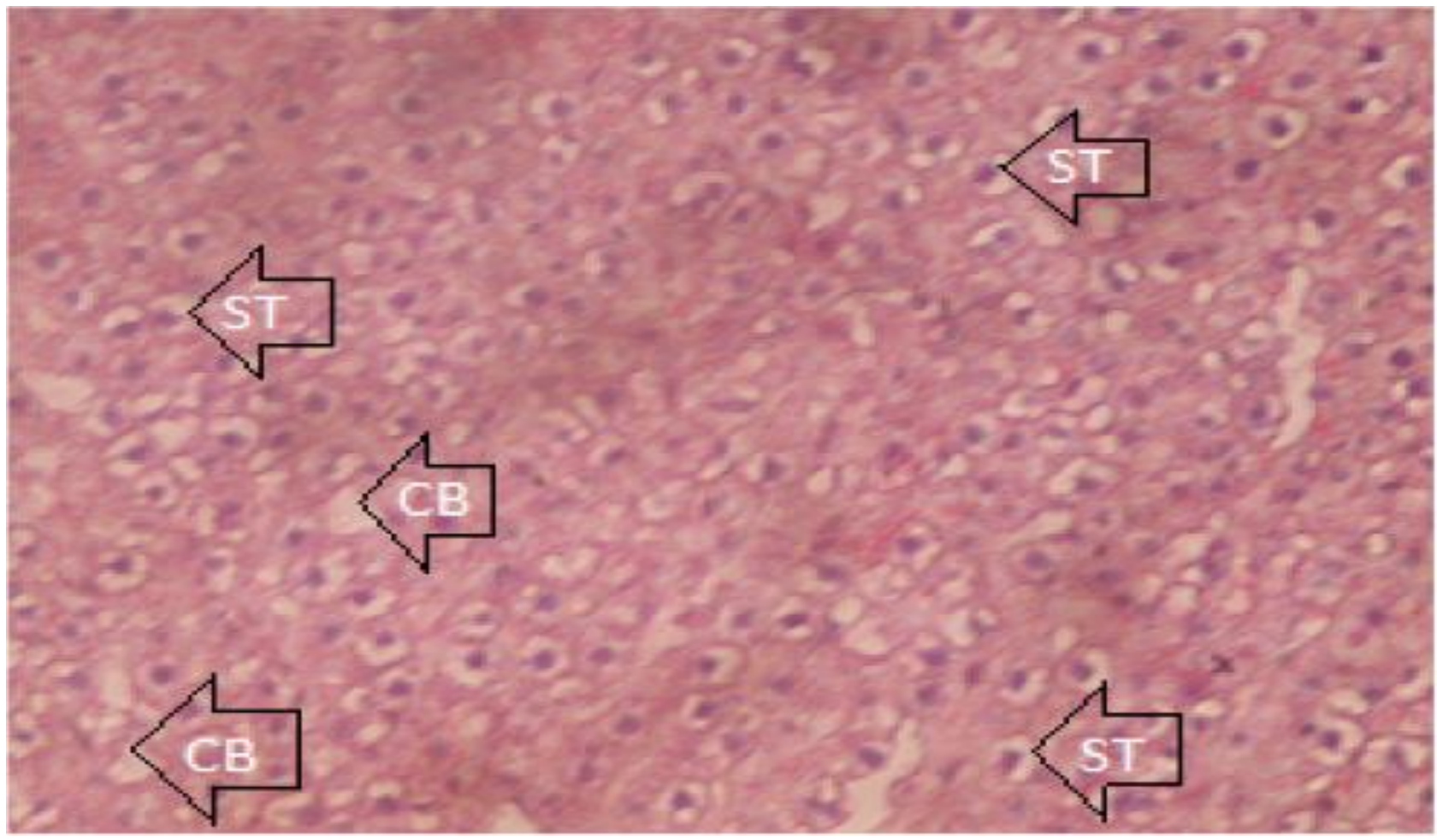

Plate 2: Photomicrograph of a section of the Liver of rat (group 2) after 28 days period. It reveals a histologically distorted liver, showing Hepatocytes (Hep) with steartosis (ST) and council man's body (CB).Magnification: x 400

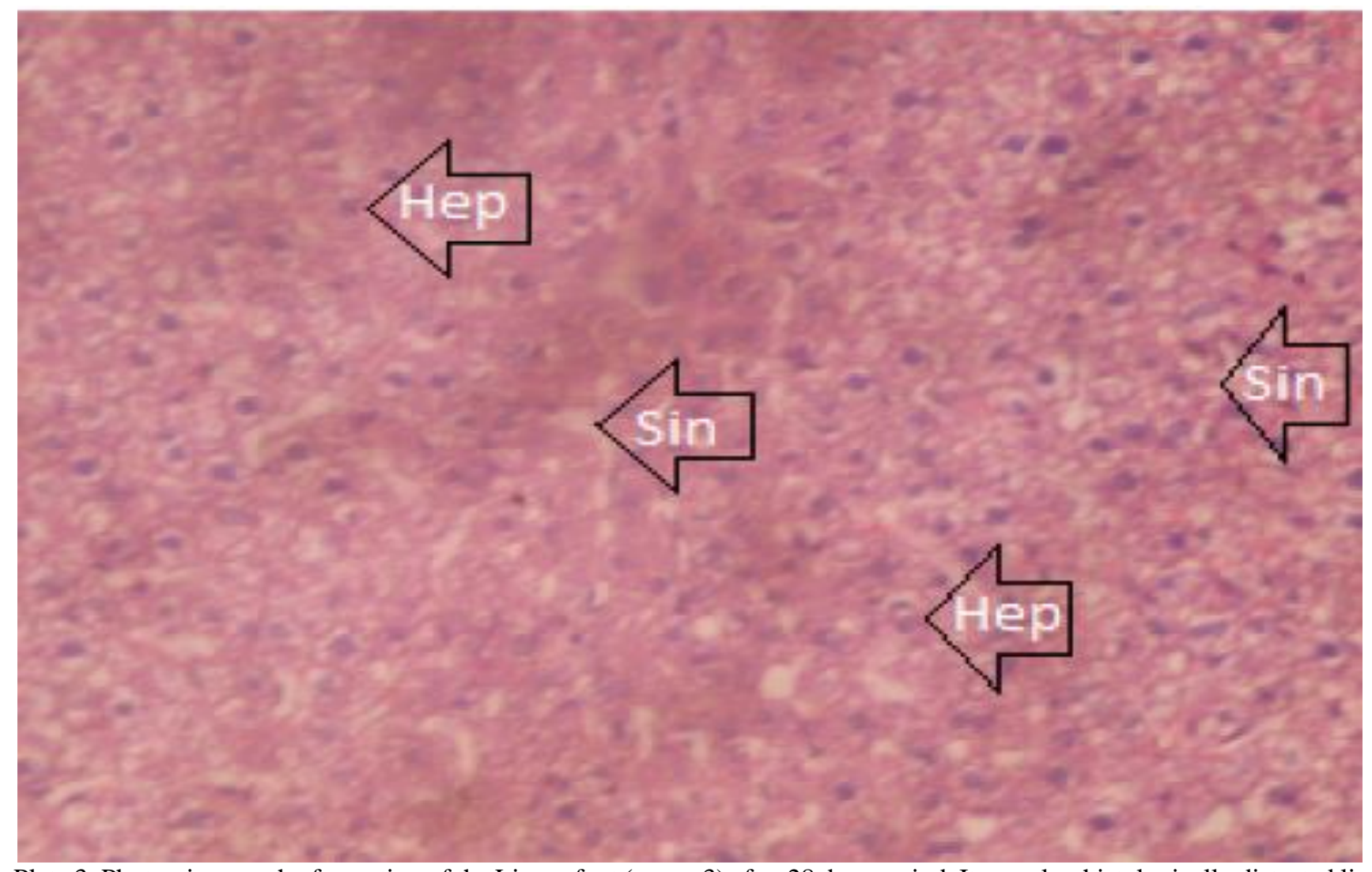

Plate 3: Photomicrograph of a section of the Liver of rat (group 3) after 28 days period. It reveals a histologically distorted liver, showing normal Hepatocytes (Hep) with sinusoids (sin). Magnification: x 400 


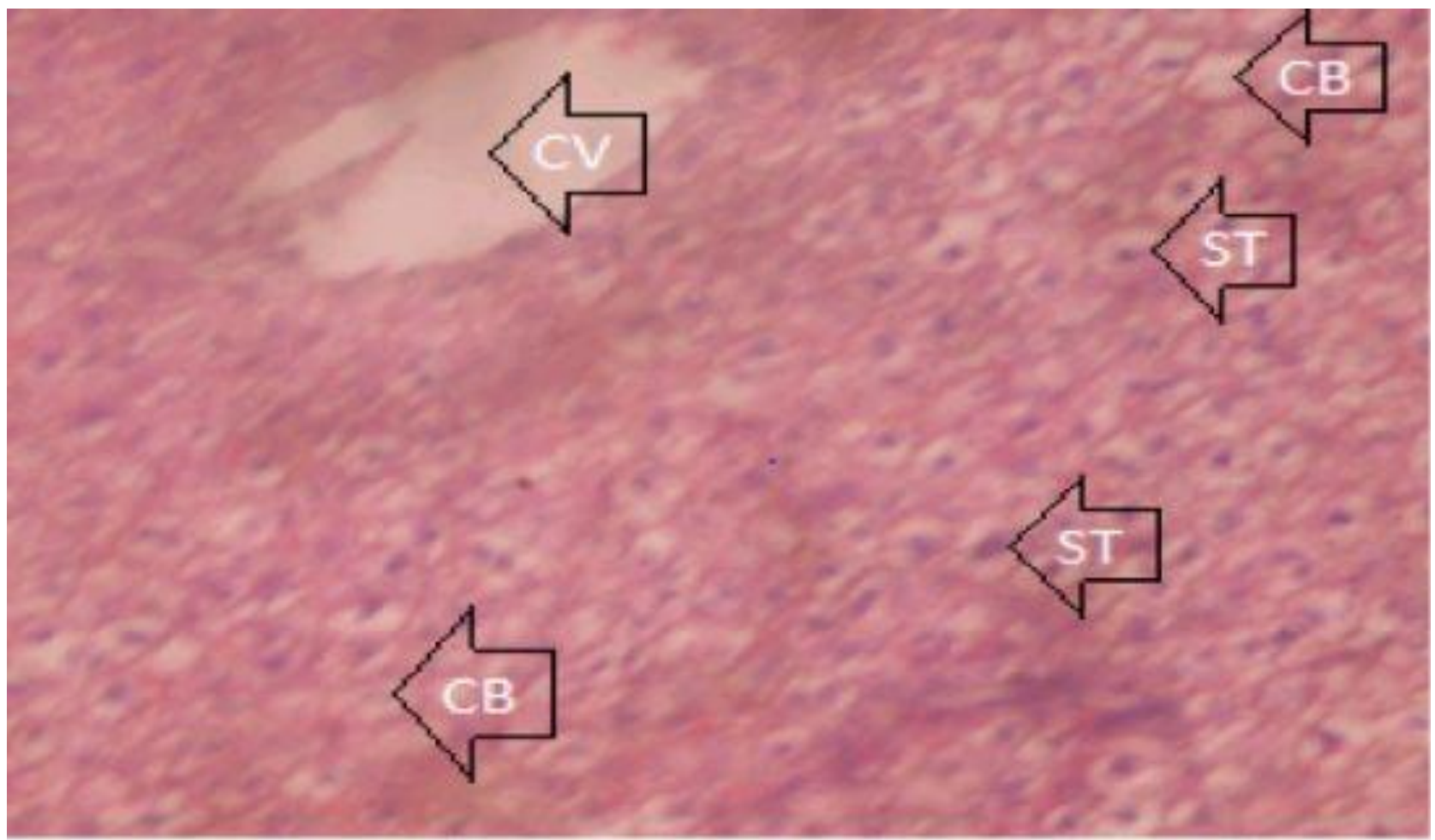

Plate 4: Photomicrograph of a section of the Liver of rat (group 4) after 28 days period. It reveals a histologically distorted liver, showing normal Hepatocytes (Hep) with council man's body (CB), steatosis (ST) and patent central vein (CV). Magnification: x 400

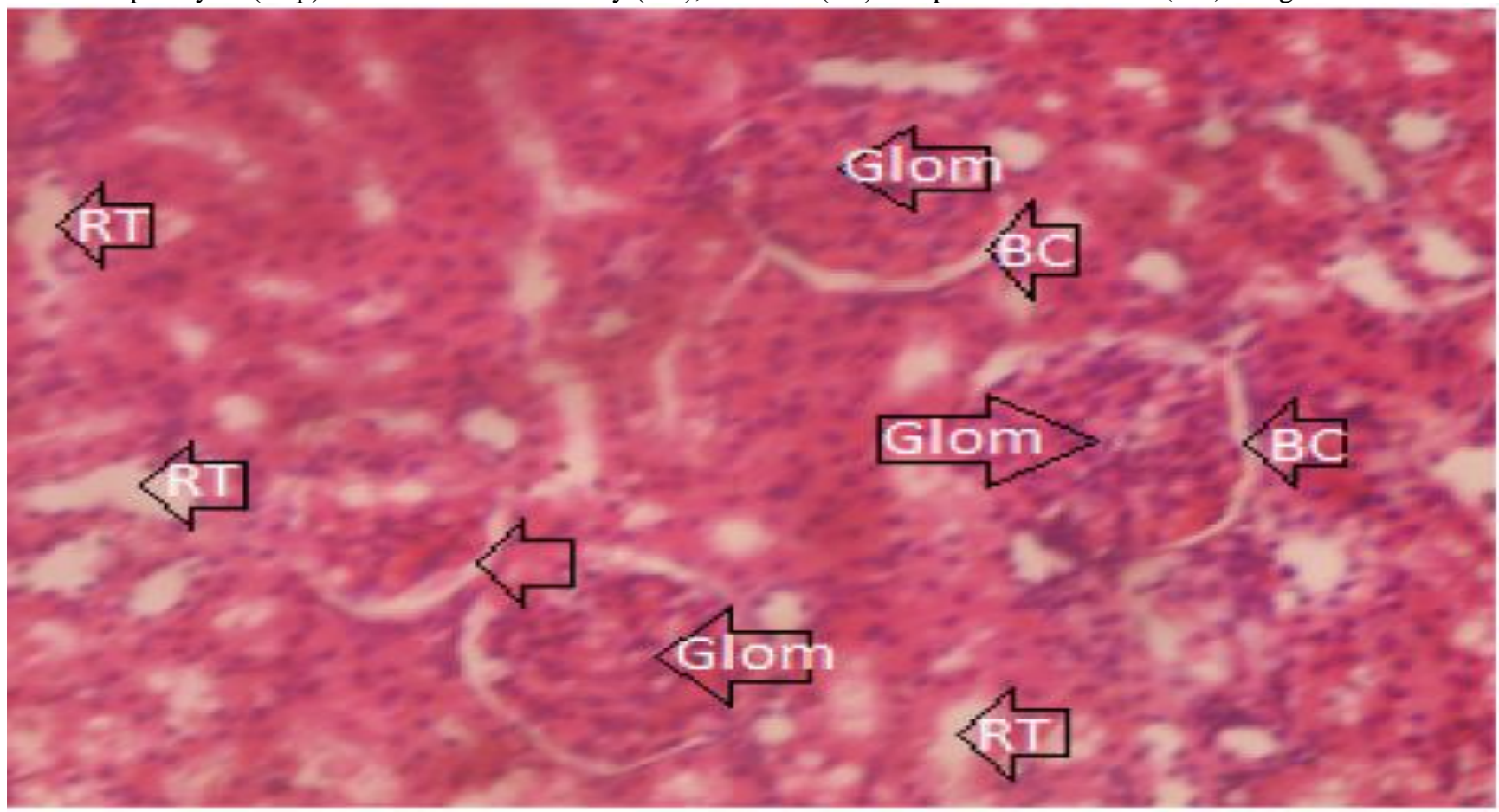

Plate 5: Photomicrograph of a section of the Kidney of rat (control group) after 28 days period. It reveals a histologically normal kidney, showing the following features:

(a) Renal tubules (RT), lined by simple columnar epithelium

(b) Glomerular tuft (Glom) containing capillaries, mesangial cells and mesangial matrix

(c) Patent Bowman's capsular space (BC) surrounding the glomerulus.

Magnification: x 400 


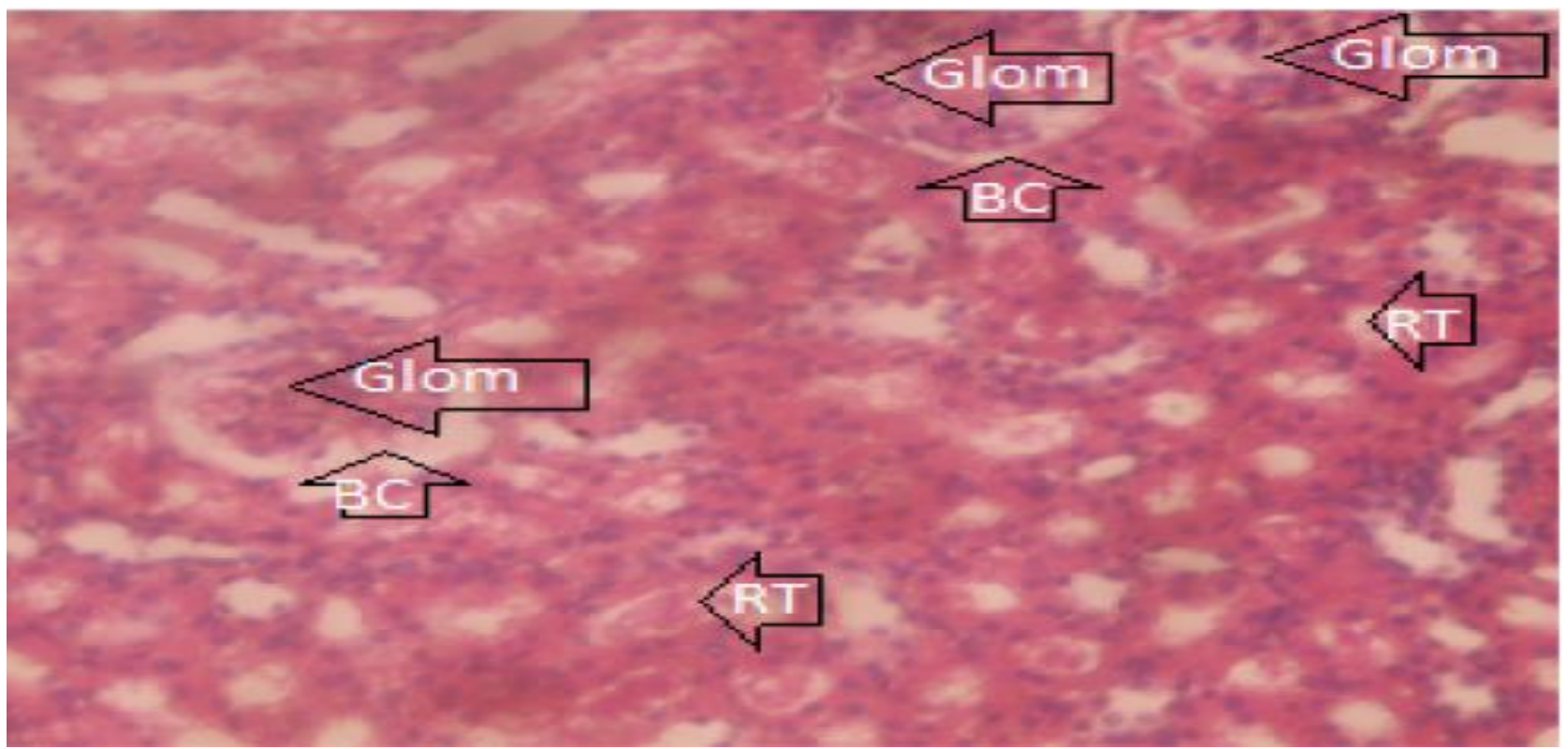

Plate 6: Photomicrograph of a section of the Kidney of rat (group 2) after 28 days period. It reveals a histologically normal kidney, showing the following features:
(a) Renal tubules (RT)
(b) Bowman's capsule (BC)
(c) Glomerulus (Glom)

Magnification: $x 400$

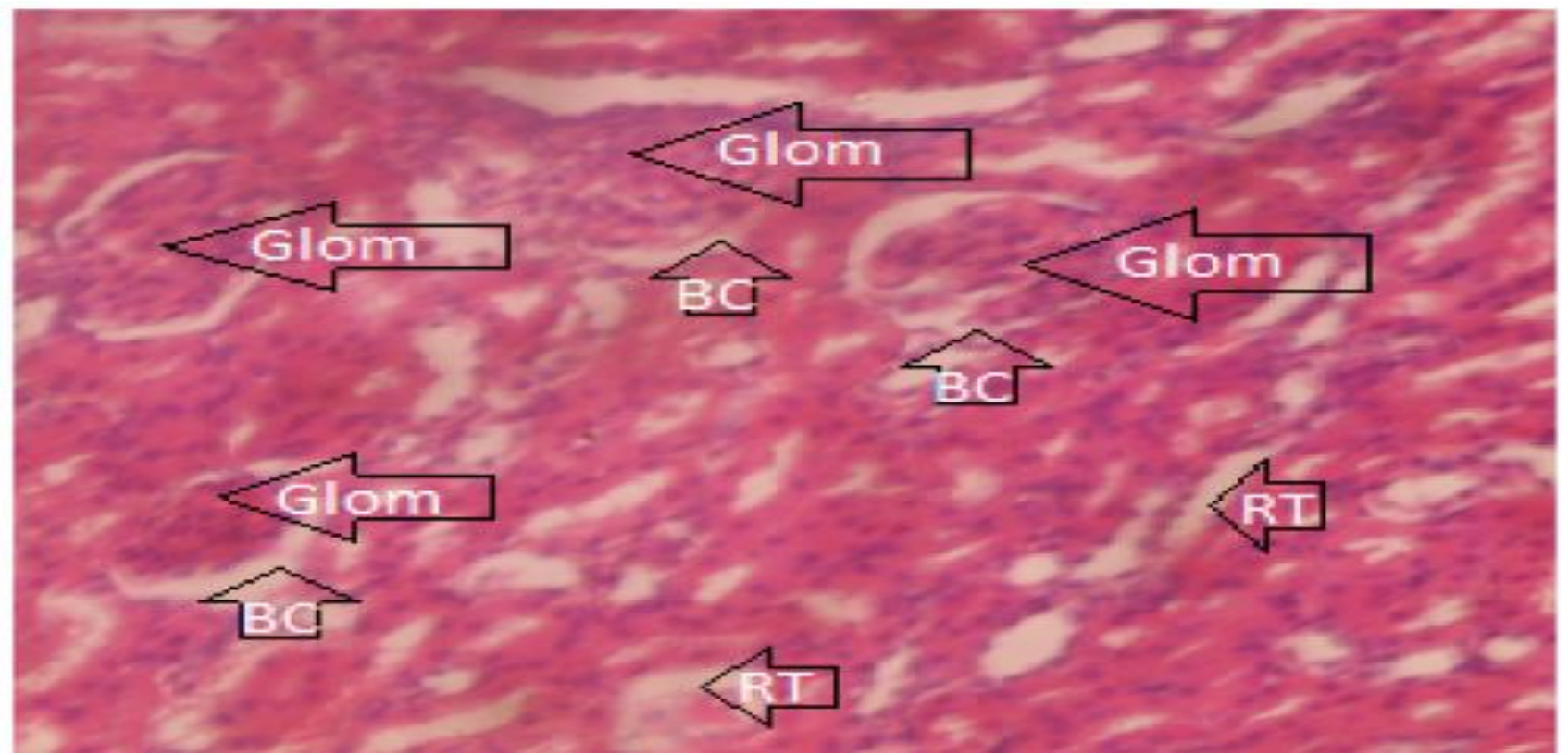

Plate 7: Photomicrograph of a section of the Kidney of rat (group 3) after 28 days period. It reveals a histologically normal kidney, showing the following features:
(a) Glomerulus (Glom)
(b) Bowman's capsule (BC)
(c) Renal tubules (RT)

Magnification: x 400 


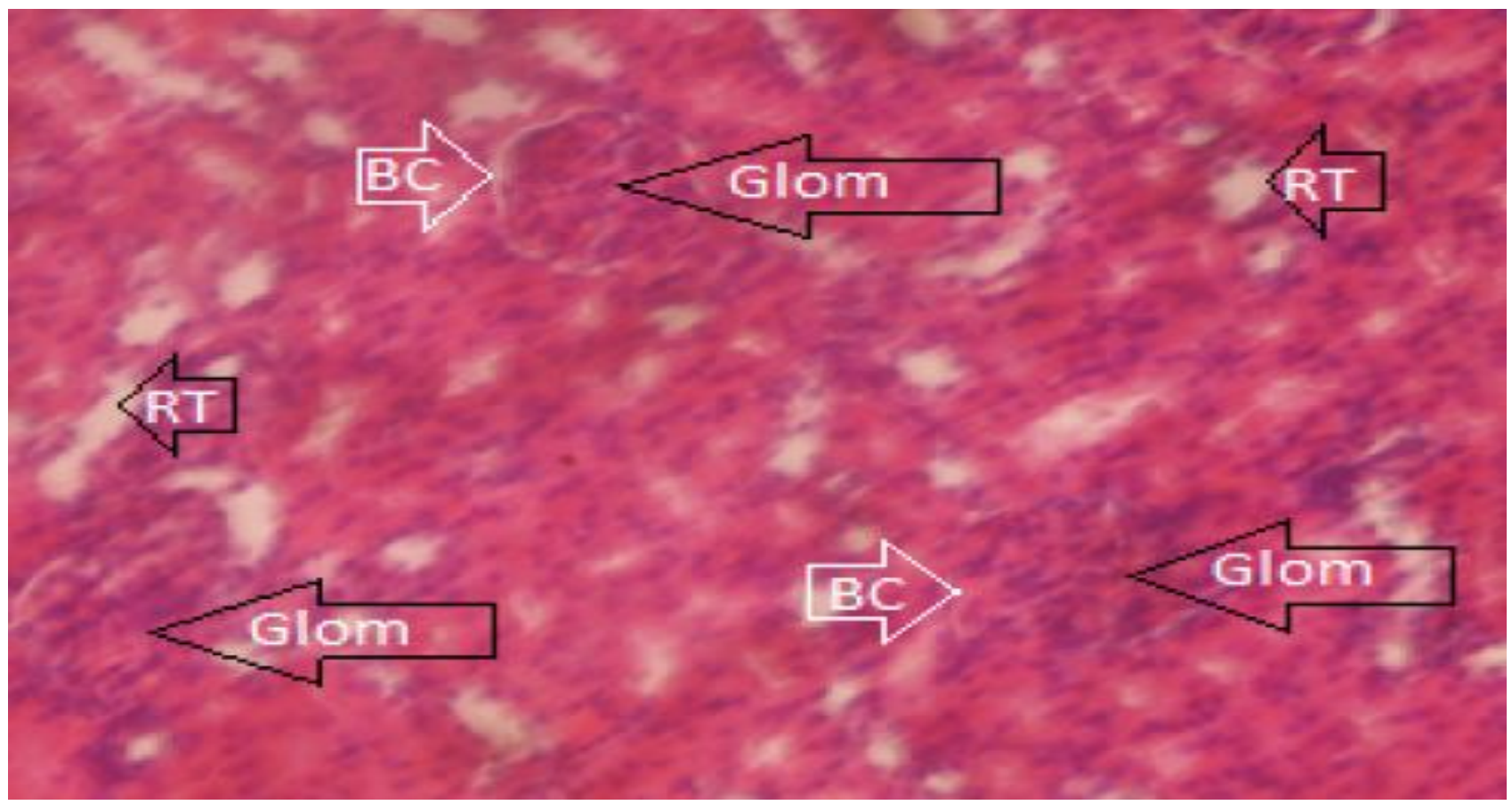

Plate 8: Photomicrograph of a section of the Kidney of rat (group 4) after 28 days period. It reveals a histologically distorted kidney, showing the following features:

(a) Obliterated Bowman's capsule (BC)

(b) Glomerulus (Glom)

(c) Renal tubules (RT)

Magnification: x 400

\section{DISCUSSION OF FINDINGS}

\section{Effect of prolonged caffeine administration on renal indices and some electrolytes}

Tables 1A and 1B show the effects of prolonged caffeine administration on renal indices and electrolytes after 28 days. It shows a statistically significant increase in the concentrations of urea, creatinine, uric acid, bicarbonate, magnesium and chloride, in relation to the control. Potassium and sodium concentrations were also found to be significantly reduced relative to the control. Electrolytes in body fluids and plasma wastes such as creatinine and urea are indicators used to determine renal function. Measuring these substances is usually sufficient to determine whether a patient has kidney disease or not. This result clearly shows that moderately high doses of caffeine can cause acute natriuresis related to diuresis. It has been pointed out that moderately high doses of caffeine will cause a sharp increase in sodium excretion, with diuretic effects. ${ }^{[3]}$ Caffeine doses greater than $90 \mathrm{mg}$ has been found to significantly increase urinary sodium excretion, but urine output only increases by $360 \mathrm{mg}$ caffeine. Oral low-dose caffeine (45mg, 90mg, and $180 \mathrm{mg}$ ) showed no significant changes in urine output. It has been pointed out that caffeine can cause acute diuresis at higher doses (> 250 $\mathrm{mg} / \mathrm{d}){ }^{[4]}$

The intrarenal mechanisms leading to the natriuretic and diuretic effects of caffeine remain to be determined. There are many conflicting views regarding the role of altered renal haemodynamics and renal tubular reabsorption. It has been pointed out that caffeine-induced sodium excretion is largely due to the inhibition of fractionated renal tubular reabsorption without affecting renal plasma flow, because sodium excretion involves hemodynamic effects. [3] However, according to scientific reviews, the probable cause is due to the antagonism of caffeine adenosine A1 receptor which inhibits the reabsorption of proximal tubule sodium, and due to the antagonism of caffeine adenosine A2 receptor. The effect leads to a decrease in distal sodium reabsorption, but the underlying mechanism behind this still remains unexplained.

This study also found that caffeine causes a slight significant reduction in plasma potassium concentration. This is compatible with the study that stated that important changes were observed in the concentration of potassium in the urine with the caffeine intake. [3] The significant increase in serum chloride and bicarbonate ions following administration of caffeine in the test rats against the control could be indicative of tubular and functional glomerular failure

The observed increase in urea and creatinine indicated that kidney function deteriorated after taking caffeine compared to the control group. Urea is the main final product of denatured proteins. The deamination of the amino acids occurs in the liver, which is the site of the urea cycle to which the urea is released, where the ammonia becomes urea and is excreted through the urine. ${ }^{[5]}$ Urea fluctuates directly with protein intake and varies from the excretion rate. Researches have shown that kidney disease that reduces glomerular filtration will result in urea retention. [6] Creatinine, on the other hand, is a product of muscle waste due to metabolism of creatine. Its blood retention is evidence of renal disorder. [5] Creatinine is muscle's waste produced by the 
metabolism of creatinine. Its retention in the blood is evidence of renal failure. ${ }^{[5]}$

\section{Effect of prolonged caffeine administration on some liver enzymes}

Table 2 shows the effect of prolonged administration of caffeine for 28 days on the concentration of liver enzymes. Compared with the control group, the concentrations of AST, ALT and ALP in groups 3 and 4 increased significantly. The results therefore showed that the prolonged administration of caffeine for 28 days caused an increase in the concentration of the liver enzymes. The level of significance of the enzyme increase was found to be dose dependent.

Liver enzymes are assumed to be the target of caffeine or other components of coffee. ${ }^{[7]}$ In a study conducted to establish how coffee consumption affects the activity of certain liver enzymes and other biochemical parameters in healthy drinkers, it was found that the mean plasma activity significantly increased ALT and AST over their baseline values. ${ }^{[8]}$ Coffee consumption has also been observed to have a lesser effect on AST compared to ALT levels. The results of this study confirmed the findings of other investigators, who observed a significant increase in the mean concentration of serum liver transaminases in coffee drinkers. ${ }^{[9,10]}$ ALT is mainly found in the cytoplasm of liver cells, while AST is mainly found in mitochondria. When liver cells suffer more severe damage, the serum level of AST will exceed that of ALT. ${ }^{[11]}$ These increases in serum liver transaminase activity may indicate that the integrity of liver cells is impaired. However, it has been reported that after stopping the consumption of coffee, serum transaminase activity returned to baseline. ${ }^{[9]}$ In addition, a group of scientists studied the effects of long-term consumption of caffeine-containing energy drink (ED) brands on the liver and kidneys of rats. All treatments were administered orally. Blood samples were drawn at the beginning of the experiment and at the 6th and 12th weeks for the determination of biochemical parameters of the liver and kidney. Histopathological studies were also performed at the end of the exposure period. It was reported that exposure to ED doses of $1.1 \mathrm{ml} / 100 \mathrm{~g}$ and 2.2 $\mathrm{ml} / 100 \mathrm{~g}$ body weight/day for 12 weeks induced highly significant increases in serum aspartate transaminase (AST), alanine transaminase (ALT), alkaline phosphatase (ALP), blood urea nitrogen (BUN), creatinine and uric acid, when compared with the control group ( $\mathrm{p}<0.001)$. ${ }^{[12]}$ Pronounced histopathological changes were also observed in hepatic and renal tissues of the EDtreated rats.

Contrary to the results of this study, other researchers have found that compared to people who drank 0 to 2 cups of coffee per day, people who drank 3 or more cups of coffee per day had significantly lower plasma liver enzyme levels. ${ }^{\text {[7] }}$ The difference in plasma activity of liver enzymes observed in this study is also inconsistent with the results of others, who reported an inverse relationship between coffee intake and liver enzymes. [13] Furthermore, a study has shown that patients who consumed more caffeine had lower levels of aspartate aminotransferase (AST), alkaline phosphate and direct bilirubin, and elevated levels of white protein in serum. ${ }^{[14]}$ Again, another group of researchers in a study found that chronic caffeine consumption in normotensive lean rats with normal kidney has no adverse effect on renal function but results in renal deterioration in pre-existing nephropathy in the presence of other risk factors. ${ }^{[15]}$

\section{Effect of prolonged caffeine administration on lipid profile and serum protein}

The results showing the effect of 28 days of administration of caffeine on Lipid profile and Serum protein with is presented in table 3. It shows a statistically significant increase in the concentrations of total cholesterol, triglycerides (TG), low density lipoprotein (LDL), high density lipoprotein (HDL), total protein (TP) and albumin.

The increase in total protein may indicate that coffee consumption has a significant effect on synthetic liver function. [16] Several studies have shown that caffeine intake by men or women does not increase the risk of cardiovascular disease, but the current recommendation is that people who already have heart problems should avoid caffeine. Some evidence suggests that there is a causal relationship between drinking coffee and higher levels of total cholesterol and serum lipids than low-density lipoprotein cholesterol. However, large amounts of caffeine or coffee have long been suspected of raising cholesterol level, but cross-sectional studies investigating these associations have yielded conflicting results. ${ }^{[17]}$ These discrepancies may reflect changes in dosage options. A study carried out by a group of researchers, showed that patients with greater caffeine increased bilirubin levels and increased levels of serum albumin. ${ }^{[14]}$

\section{Effect of prolonged caffeine administration on body weight}

Table 4 shows the effect of prolonged caffeine administration on the body weight of both the control and test groups for 28 days. The results show an increase in body weight in the control group and a statistically significant decrease in the body weight of the treatment groups, relative to the control group. It also shows that the weight loss after caffeine intake is dose dependent and proportional to the duration of caffeine intake. This result is consistent with the results obtained by other researchers, who reported that increased consumption of tea and coffee is related to decreased weight gain, and increased caffeine intake can lead to long-term slightly reduced weight gain. ${ }^{[18]}$ Although the mechanism through which caffeine causes weight loss was not investigated in this work, one possible mechanism might be via its negative effect on the medial hypothalamus, the centre in the forebrain responsible for the stimulus of hunger.

\section{Effect of caffeine consumption on the histology of the liver}

Plate 1 shows the result of the liver histology of the control group while plates 2, 3 and 4 show the results of the histology of the liver of the caffeine treated groups after 28 days of administration. The control shows a histologically normal liver, with normal Hepatocytes (Hep) and sinusoids (sin) while the experimental groups (groups 2-4) show a histologically distorted liver revealing normal hepatocytes (Hep) with steartosis (ST), council man's body (CB) and Central Vein (CV) with congestions. This shows that the caffeine may have the capacity of destroying the liver. Caffeine is mainly metabolized by the cytochrome P450 enzyme, which is responsible for more than $90 \%$ of caffeine removal. It is said that caffeine may have toxic or preventive effects under certain physiological or pathological conditions, depending on the dosage, previous long-term exposure and other factors. In previous studies, long-term use of caffeine has been shown to exacerbate liver damage. Carbonated drinks containing 
caffeine are also associated with high blood pressure, diabetes and kidney stones, which are risk factors for chronic kidney disease.

\section{Effect of caffeine on the histology of the kidney}

The result of the effect of 28 days of caffeine consumption on the histology of the kidney of the control group is shown in plate 5 while that of groups 2, 3 and 4 (the experimental groups) are shown in plates 6,7 and 8 respectively. The control shows a histologically normal Kidney, with Renal tubules (RT), lined by simple columnar epithelium, glomerular tuft (Glom) containing capillaries, mesangial cells, mesangial matrix and Patent Bowman's capsular space (BC) surrounding the glomerulus. Groups 2 and 3 also show a histologically normal liver, containing glomerulus (Glom), Bowman's capsule (BC) and renal tubules (RT). However, group 4 showed a histologically distorted Kidney, with obliterated Bowman's capsule (BC), Glomerulus (Glom) and renal tubules (RT). This result reveals that at a very high concentration, the caffeine may have the capacity to destroy the kidney. Studies have shown that drinking 3-4 cups of coffee and other caffeinated products increases the risk of kidney disease and speeds up the decline in kidney function. ${ }^{[1]}$ Studies have also shown that long-term caffeine intake increases the rate of impaired kidney function. ${ }^{[1]}$ Long term use of caffeine has also been seen to worsen bladder instability and also worsen the rest of those with bladder problems.

Contrary to our result here, a study found that chronic caffeine consumption in normotensive lean rats with normal kidney has no adverse effect on renal function but results in renal deterioration in pre-existing nephropathy in the presence of other risk factors. ${ }^{[15]}$

\section{CONCLUSIONS}

The study showed that the long-term use of caffeine has the capacity to aggravate cardiovascular disorders by elevating the concentration of plasma lipid profile. It is also found that the chronic consumption of caffeine can result in electrolyte imbalance with its attendant consequences via the decrease in the plasma concentrations of sodium and potassium. Also, the longterm use of caffeine has been found to cause liver and kidney dysfunction. Finally, taking caffeine can cause significant weight loss, especially when taken for a long time.

\section{ETHICAL APPROVAL}

This study was approved by the Ethics Committee of the University of Port Harcourt. A good laboratory practice protocol was followed during all experiments. Quality standards for biomedical research were also implemented.

\section{ACKNOWLEDGEMENTS}

The authors would like to express warm appreciation to Professors DV Dapper and IM Siminialayi of the Department of Human Physiology and Pharmacology respectively, College of Health Sciences, University of Port Harcourt, Nigeria for their immense technical assistance.

\section{SOURCE OF FUNDING}

None

\section{COMPETING INTERESTS}

Authors have declared that no competing interests exist.

\section{AUTHOR'S CONTRIBUTIONS}

Author Ekamadu Hope Ukame conceived the study, designed the protocol and coordinated the experiment while author Ojeka Sunday Ogbu carried out the animal feeding, laboratory procedures and manuscript writing. Finally, author Zabbey Victor Zigabelbari performed the statistical analysis, data interpretation and contributed in the manuscript writing. All authors read through and approved the final manuscript.

\section{REFERENCES}

[1] Kennedy, O. J., Roderick, P., Poole, R. and Parkes, J. (2017). Coffee and kidney disease. Int J Clin Pract, 71. doi:10.1111/ijcp.12980

[2] Apurva A Modi, Jordan J, Yoon Park, David E Kleiner, James E. Everhart Jake Liang, and Jay H. Hoofnagle (2010): Increased caffeine consumption is associated with reduced hepatic fibrosis. Hepatology,51 (1): 201-209. doi: 10.1002/hep.23279

[3] D. G. Shirley, S. J. Walter and F. H. Noormohamed (2002). Natriuretic effect of caffeine: assessment of segmental sodium reabsorption in humans. Clinical Science, 103, 461-466.

[4] Armstrong LE, Pumerantz AC, Roti MW. (2005). Fluid, electrolyte, and renal indices of hydration during 11 days of controlled caffeine consumption. Int $\mathrm{J}$ Sport Nutr Exerc Metab 15(3):252-265.

[5] David Weiner, William E. Mitch and Jeff M. Sands (2017). Urea and Ammonia Metabolism and the Control of Renal Nitrogen Excretion. Clin J Am Soc Nephrol. 10(8): 1444-1458

[6] Ranjna, C. (1999): practical clinical Biochemistry methods and interpretation, 2nd ed. p.117

[7] Casiglia E, Spolaore P, Ginocchio G, Ambrosio GB (1993). Unexpected effects of coffee consumption on liver enzymes. Eur J Epidemiol. 9(3): 2937.

[8] Onuegbu AJ, Olisekodiaka JM, Adebolu OE, Adesiyan A, Ayodele OE (2011). Coffee consumption could affect the activity of some liver enzymes and other biochemical parameters in healthy drinkers. Med Princ Pract. 20(6): 514-8.

[9] Urgert R, Essed N, Van der Weg G, Kosimeijer-Schuil TG, Katan MB (1997). Separate effects of the coffee diterpenes cafestol and kahweol on serum lipids and liver aminotransferases. Am J Clin Nutr.65:519-524.

[10] Honjo S, Kono S, Coleman MP, ShinchiK,Sakurai Y \& Todoroki I, Umeda. (2001). Coffee consumption and serum aminotransferasesin middle-aged Japanese men. J Clin Epidemiol, 54: 823-829.

[11] Burtis CA, Ashwood ER (2001). Liver function; in Burtis CA, Ashwood ER (eds): Tietz Fundamentals of Clinical Chemistry, ed 5. Philadelphia, Saunders, pp 747-770.

[12] Wael Mansy, Deema M Alogaiel, Mona Hanafi, Enas Zakaria (2017). Effects of chronic consumption of energy drinks on liver and kidney of experimental rats. Tropical Journal of Pharmaceutical Research. 16 (12): 2849-2856.

[13] Bravi F, Bosetti C, Tavani A, Bagnardi V, Gallus S, Negri E, Franceschi S. (2007). Coffee drinking and hepatocellular carcinomarisk: a meta-analysis. Hepatology; 46: 430-435.

[14] Apurva A Modi, Jordan J Feld, Yoon Park, David E Kleiner, James E. Everhart, T. Jake Liang, MD, Jay H. Hoofnagle (2010). Hepatology. 51(1): 201-209.

[15] Stevan and Sheldon (2002). Long term caffeine consumption exacerbates renal failure in obese diabetic rats. Kidney international, 61(4): 1433-44. 
[16] Anaelechi J. Onuegbu, Japhet M. Olisekodiaka, Olubukunmi E. Adebolu, Adekunle Adesiyan, Olugbenga E. Ayodele (2011). Coffee Consumption Could Affect the Activity of Some Liver Enzymes and Other Biochemical Parameters in Healthy Drinkers. Med Princ Pract. 20:514-518.

[17] D'Avanzo B, Santoro L, Nobill A (1993). Coffee consumption and serum cholesterol. Prev Med. 22:219-24.

[18] Esther Lopez-Garcia, Rob M van Dam, Swapnil Rajpathak, Walter C Willett, JoAnn E Manson, Frank B Hu (2006). Changes in caffeine intake and longterm weight change in men and women. The American Journal of Clinical Nutrition. 83(3):674-680.

\section{AUTHORS}

First Author - Ekamadu Hope Ukame, Department of Human Physiology, Faculty of Basic Medical Sciences, College of Health Science, University of Port Harcourt, Rivers State, Nigeria., ekamaduhope@gmail.com
Second Author - Ojeka Sunday Ogbu, Department of Human Physiology, Faculty of Basic Medical Sciences, College of Health Science, University of Port Harcourt, Rivers State, Nigeria., sunday.ojeka@uniport.edu.ng

Third Author - Zabbey Victor Zigabelbari, Department of Human Physiology, Faculty of Basic Medical Sciences, College of Health Science, University of Port Harcourt, Rivers State, Nigeria., zabbeyvictor@gmail.com

Correspondence Author - Ojeka Sunday Ogbu, Department of Human Physiology, Faculty of Basic Medical Sciences, College of Health Science, University of Port Harcourt, Rivers State, Nigeria., E-mail: sunday.ojeka@ uniport.edu.ng Phone: +2348033854898 